\title{
The Geography of Patient Safety: a topical analysis of sterility
}

Citation for published version (APA):

Mesman, J. (2009). The Geography of Patient Safety: a topical analysis of sterility. Social Science \& Medicine, 69(12), 1705-1712. https://doi.org/10.1016/j.socscimed.2009.09.055

Document status and date:

Published: 01/01/2009

DOI:

10.1016/j.socscimed.2009.09.055

Document Version:

Publisher's PDF, also known as Version of record

Document license:

Taverne

Please check the document version of this publication:

- A submitted manuscript is the version of the article upon submission and before peer-review. There can be important differences between the submitted version and the official published version of record.

People interested in the research are advised to contact the author for the final version of the publication, or visit the DOI to the publisher's website.

- The final author version and the galley proof are versions of the publication after peer review.

- The final published version features the final layout of the paper including the volume, issue and page numbers.

Link to publication

\footnotetext{
General rights rights.

- You may freely distribute the URL identifying the publication in the public portal. please follow below link for the End User Agreement:

www.umlib.nl/taverne-license

Take down policy

If you believe that this document breaches copyright please contact us at:

repository@maastrichtuniversity.nl

providing details and we will investigate your claim.
}

Copyright and moral rights for the publications made accessible in the public portal are retained by the authors and/or other copyright owners and it is a condition of accessing publications that users recognise and abide by the legal requirements associated with these

- Users may download and print one copy of any publication from the public portal for the purpose of private study or research.

- You may not further distribute the material or use it for any profit-making activity or commercial gain

If the publication is distributed under the terms of Article $25 \mathrm{fa}$ of the Dutch Copyright Act, indicated by the "Taverne" license above, 


\title{
The geography of patient safety: A topical analysis of sterility ${ }^{\text {ts }}$
}

\author{
Jessica Mesman* \\ Department of Technology E Society Studies, Maastricht University, P.O. Box 616, Maastricht, 6200 MD, Netherlands
}

\section{A R T I C L E I N F O}

\section{Article history:}

Available online 24 October 2009

\section{Keywords:}

Netherlands

Patient safety

Neonatology

Space

Sterility

Geography

Medical boundaries

\begin{abstract}
A B S T R A C T
Many studies on patient safety are geared towards prevention of adverse events by eliminating causes of error. In this article, I argue that patient safety research needs to widen its analytical scope and include causes of strength as well. This change of focus enables me to ask other questions, like why don't things go wrong more often? Or, what is the significance of time and space for patient safety? The focal point of this article is on the spatial dimension of patient safety. To gain insight into the 'geography' of patient safety and perform a topical analysis, I will focus on one specific kind of space (sterile space), one specific medical procedure (insertion of an intravenous line) and one specific medical ward (neonatology). Based on ethnographic data from research in the Netherlands, I demonstrate how spatial arrangements produce sterility and how sterility work produces spatial orders at the same time. Detailed analysis shows how a sterile line insertion involves the convergence of spatially distributed resources, relocations of the field of activity, an assemblage of an infrastructure of attention, a specific compositional order of materials, and the scaling down of one's degree of mobility. Sterility, I will argue, turns out to be a product of spatial orderings. Simultaneously, sterility work generates particular spatial orders, like open and restricted areas, by producing buffers and boundaries. However, the spatial order of sterility intersects with the spatial order of other lines of activity. Insight into the normative structure of these co-existing spatial orders turns out to be crucial for patient safety. By analyzing processes of spatial finetuning in everyday practice, it becomes possible to identify spatial competences and circumstances that enable staff members to provide safe health care. As such, a topical analysis offers an alternative perspective of patient safety, one that takes into account its spatial dimension.
\end{abstract}

(C) 2009 Elsevier Ltd. All rights reserved.

\section{Introduction}

In hospital settings, errors may lead to adverse events, some with irreversible consequences. Several studies have shown that these incidents and near misses happen at an unacceptably high level (Department of Health, 2000; Kohn, Corrigan, \& Donaldson, 2000). These findings have impelled the rise of a patient safety movement. The main focus in patient safety research is on detection and elimination of causes of incidents. While numerous hospitals produce information about incidents, Smith, Goodwin, Mort, and Pope (2006) demonstrate the ambiguity of the official definitions of reporting systems. In practice apparently, clear definitions of 'critical incident' and 'criticality' are operationalized within the implicit safety culture of the ward. These personal working interpretations influence the discussion and reporting of

\footnotetext{
is I would like to thank Twan Mulder, neonatologist, my colleagues Jens Lachmund and Ruth Benschop, and the anonymous reviewers of this article for their constructive contribution.

* Tel.: +31433883339.

E-mail address: j.mesman@maastrichtuniversity.nl
}

adverse incidents. Moreover, they argue that educationally useful events fall outside the critical incident reporting. Also, Sharma, Smith, Rooksby, and Gerry (2006) stress how official incident reporting systems do not provide an adequate learning environment. To improve the educational value of incident reporting, it should facilitate peer discussion of specific incidents. Moreover, as I will argue here, defining patient safety as the absence of errors and incidents is too narrow a definition. Because patient safety is more than the absence of incidents, a focus on patient safety should involve more than 'error-free' forms of action and reasoning. We can define patient safety on the basis of what it is, instead of what it is not. Now, instead of being the error-free counterpart, safe practices can also be defined on the basis of their own modalities. This change of focus will bring other elements of patient safety to our attention and yield another set of questions. As such, this type of research does not aim to repair discredited practices but aims to question dominant ways of understanding safety.

We can ask ourselves why things don't go wrong more often. After all, patient safety is a remarkable accomplishment when we realize, for example, how complicated intervention processes on critical care units have become. This is why patient safety research 
should also include analysis of the resources of strength within sound and safe practices. To identify the strength of practices, this study is not about their troubles, mistakes, imperfection, inadequacies and flaws, which we need to eliminate and can learn from, but about things that go well and how they are supposed to be. Therefore, not only what is missing, the so-called gaps in the safety net, but also the fibre of the safety net itself, the elements that constitute the fabric of 'normal' practice, should be taken into consideration when we aim to strengthen what is already strong to preserve and improve patient safety.

A key question in this kind of research, then, is the following: how are those in complex care practices capable of providing a safe and sound performance despite the imperfections of the sociotechnical environment they work in? In answering this question, I would like to argue that one should not just focus on the explicit, intentional or formal safety measures that make up the constituents of patient safety, such as protocols and technological equipment designs. One should also analyze the informal or implicit elements of the safety structure. Patient safety is also achieved through an unplanned, and perhaps unarticulated, set of actions and initiatives that can still be effective. This implies that the nonintentionally built-in structures of a practice that contribute to the constitution of patient safety, and its supportive contextual contingencies, have to be taken into account as well. The aim to articulate the informal resources of strength should be understood as an attempt of 'exnovation' (Mesman, 2008). Exnovation refers to the effort to foreground what is already present - though hidden in specific practices (Wilde de, 2000). It challenges the dominant trend to overlook existing practices. Importantly, 'things or practices are not less valuable simply because they already exist' (Wilde de, 2000, p. 13). Rather, exnovation takes into account that which is already evident in medical practice, and patient safety in particular.

To study what is already in place yet hidden, is hardly an easy task. We can use the most basic formative pillars of a practice, namely its spatial, temporal and socio-technical order, as entry points for analysis. A focus on these pillars can provide us the analytical entrance we need to identify the already present but, as yet, unrecognized aspects of the contexture of the safety net. In this article, I will focus on the spatial dimension of patient safety by executing a topical analysis of the production and preservation of sterility while inserting a central venous catheter. Although this analysis is based on the observation of numerous insertion procedures, it describes only one. Using a single case study as research strategy is motivated by the aim to provide a rich, complex description of medical intervention in order to 'exnovate' the involved spatial dynamics. A thick description of one singular case will enrich our understanding of the spatial dynamics involved in 'routine' interventions, like the insertion of a central catheter. With this analytical focus, I will study how space matters in regard to patient safety. To this aim, the next section will provide a short introduction to spatial studies and an introduction of the case study. The third section will present a fine-grained analysis of the insertion of an intravenous line in a newborn baby who is admitted on an intensive care unit. To prevent infections, this procedure requires a high level of sterility of the instruments and environment. My analysis will demonstrate the crucial role of spatial ordering in sterility work. The fourth section studies how sterility work itself re-arranges the spatial order of the ward. The paper concludes with a reflection on the relevance of spatial studies for patient safety.

\section{Spatiality and patient safety on a NICU}

Space is not just a matter of measurable distance and location, but can be conceptualized as 'a cultural and symbolic phenomenon constructed through relationships between people and their setting' (Andrews \& Moon, 2005a, p. 56). The complex interactions between spatial structures and social structures (on the individual and collective level) are considered as essential elements of our understanding of space and place. The relationship between humans and their environment has been an object of research in different social sciences. Sociological studies relate the specificity of the physical structure to the social structure (for example, in terms of identity and power relations) while analysis in science studies has revealed the implications of the physical setting for the production of knowledge. Examples of these kinds of sociological studies are the work of Bourdieu, Giddens, Goffman and Foucault. Examples in science studies are Gieryn (2002), Hetherington and Munro (1997), Livingstone (2003), Ophir and Shapin (1991), and Smith and Agar (1998).

In health-related disciplines, we also see a growing number of spatial studies. Some scholars even refer to a 'spatial turn' (Andrews \& Moon, 2005b; Carolan, Andrews, \& Hodnett, 2006). It started in the 1960s with medical geography, a sub-discipline of human geography. This field concentrated on landscape epidemiology as its main activity, focussing on the spatial distribution and patterning of diseases. In the 1980s, spatial studies in health care moved away from mapping and modelling place towards 'being in place' and 'being at a location'. Now the focus was on the role and meaning of places in relation to health and health care. These studies, from then on called 'health geography', analyzed the impact of places on the way people experience health and how, in turn, health and illness influence spatial experiences (Andrews \& Moon, 2005a, 2005b). Today, health geography includes, alongside landscape epidemiology, studies of therapeutic landscapes, which pay attention to the specific locations in which people are cared for and the healing qualities of these places, ranging from regions and towns to hospital wards. Other studies in health geography focus on the spatial accessibility and utilization of health care services. The spatial turn in health care has affected the field of nursing as well. Although nursing science has been interested in the role of location on health since the time of Florence Nightingale, we have witnessed the emergence of a more explicit spatial focus since the early 2000s. This geography of nursing focuses on issues like patient-nurse proximity (Malone, 2003) or the 'politics of space' that highlights the socio-spatial power structures of nurses (Andrews, 2003; Gilmour, 2006).

In line with this spatial turn in health care research, I would like to pay attention to the spatiality of patient safety research. How can we think 'geographically' about patient safety? What is the significance of space for the production and preservation of patient safety? In what ways do sterile work affect the spatial order? Do safety activities bear the imprint of their location? An analysis of the spatiality of patient safety requires both a focus on the (coordinating) role of the (material) environment as well as an analysis of the way spatial order is produced by safety activities. To gain insight into the spatiality of patient safety, I will focus on one specific kind of space: sterile space, and one specific medical procedure: the insertion of a central venous catheter. What, in this procedure, is the role of spatial ordering in maintaining an adequate level of sterility?

To answer this question, I turn my focus to a Neonatal Intensive Care Unit (NICU) in the Netherlands where I did participant observation for eight months during Spring 2007 and 2008. It was decided by the hospital that ethical approval was not required for the study, as it did not involve any invasive interaction with the patients. Nevertheless, with the help of the hospital's legal department I did develop and use informed consent forms for the parents and staff. A NICU is specialized in the care of newborns. Newborn babies end up here because their lives are seriously at risk 
on account of complications linked to their delivery, congenital diseases, infections, or premature birth. The vulnerability of newborns calls for a strictly controlled environment, which basically means that the NICU itself is one giant incubator. The temperature is constantly held at $28^{\circ} \mathrm{C}$, the air humidity has to be kept up, and hygiene rules need to be strictly adhered to. This is why parents and staff have to pass through an airlock when entering the neonatology ward. The airlock marks the transition from the cold, contagious outside world to the warm, clean, carefully regulated world inside. Overpressure and hygiene rules should ensure that bacteria are kept out. Both staff and parents have to perform several mandatory acts: store their coat, bag and jewellery (favourite hiding places for bacteria) in lockers, put on a gown or uniform and wash hands and wrists vigorously. Only after attending to these ritual procedures they are allowed to pass through the second door that leads into the NICU. However, the airlock is not watertight. Some bacteria still know how to find their way in. This is why upon re-entering the intensive care unit one has to use alcohol-based disinfectant. Besides the airlock, other architectural features, like the alcohol dispensers at every bedside or the negative pressure in the isolation room in case of a potential contagious infection of a new admission from outside the hospital, reflect an awareness of the vulnerability of this particular patient population.

The awareness of the vulnerability of this patient population is not limited to physicalized safety measures such as the airlock and the isolation box. The spatiality of patient safety exceeds the domain of architectural design. To study the role of spatial order in the production of patient safety, and sterility in particular, I will follow a neonatologist and a nurse while they carry out a line insertion of a central venous catheter. What is the role of the spatial order in their efforts to work with sterile instruments in a sterile environment? What kinds of spatial arrangements can we identify in the production of sterility? What is the relation between the spheres of action and the degree of sterility? To explore these questions, we now turn to the concrete practice of sterility work in the NICU.

\section{On the NICU}

This morning a baby girl of 28 weeks was admitted to the NICU. The attending neonatologist decides to insert a central venous catheter. He walks to the incubator, opens its windows and switches on the light to see the baby's veins. He examines her legs and arms to find the best place to insert the line. While gently rubbing the baby's skin, he opts for the brachial vein, the large vein that runs up from the arm to the shoulder. He takes a tape measure from the table next to the incubator to determine the length between the insertion site in the arm and the position where the superior vena cava, a large blood vessel that leads to the heart, is located. He estimates having to insert the line approximately 8 centimetres. While closing the incubator, he informs the nurse responsible for the baby about the location and size of the catheter. After switching off the light, the neonatologist walks up to the cabinet in the other corner of the NICU to take out a cap and a facemask, after which he heads for the sink (Fig. 1).

Very ill or premature newborns lack the strength to feed themselves. Therefore, a small polyurethane tube is inserted into the baby's bloodstream. This catheter provides access to the baby's body to administer medication and parental nutrition. Central catheters are used when it is expected that the baby needs intravenous infusions for an extended period of time. In this way, they

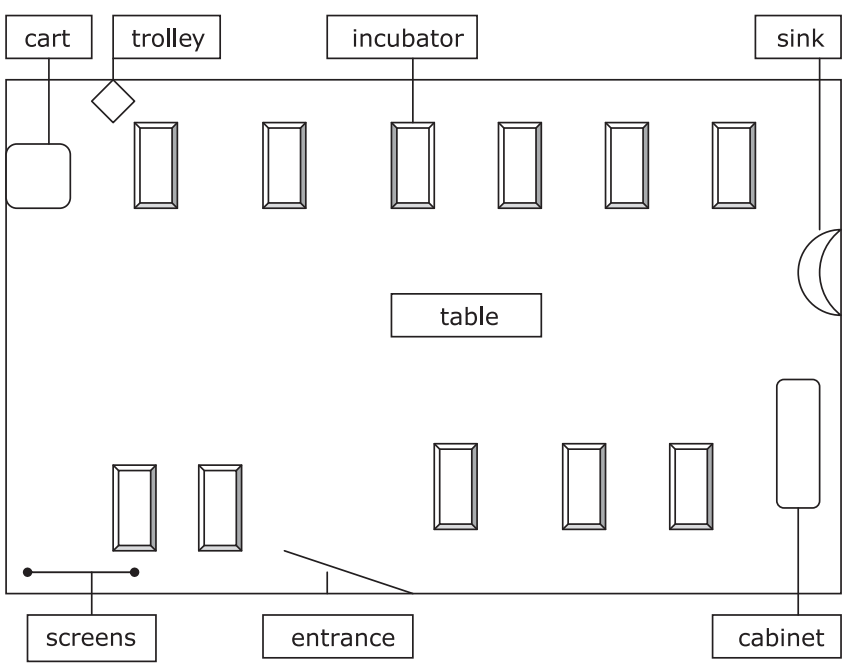

Fig. 1. Explanatory sketch of the spatial arrangement of the NICU before the insertion procedure.

can avoid the stress and discomfort of repeated needle sticks because these central catheter's lines can stay in as long as 3 weeks.

Although intravenous access is essential for optimal management of the vulnerable patient population one finds on the NICU, the deployment of this technique is not without risk. Intravenous access can cause infections, the so-called catheter-related bloodstream infections (CRBSIs). Vascular infections make up a huge part of the nosocomial, or hospital acquired, infections and contributes substantially to hospital morbidity and mortality rates. Estimations present figures of around 50,000-100,000 bloodstream infections per year in the United States alone. Ninety percent of these infections are related to central venous catheters (Sheretz, Wesley Ely, \& Westbrook, 2000). To prevent CRBSI, several strategies have been developed, ranging from finding the best insertion site, skin preparation with chlorhexidine, maintaining proper nurse staffing levels and the use of catheters with anti-infective coatings or antibiotic impregnated catheters to the use of maximal barrier precautions (MBP). The optimal safety strategy is to use all of these strategies (Rubinson \& Diette, 2004:Rizzo, 2005). Whatever the strategy, the various preventative actions all aim to keep the germs out by working with sterile instruments in a sterile environment. In the next section, I will take a closer look at these precautions and the role of spatial order in particular.

\section{Convergence and composition: the spatial arrangement of distributed resources of sterility}

\section{Next to the sink: the focus of attention}

The nurse walks over to the cabinet as well, also puts on a facemask and cap, and hands over a brush to the neonatologist to scrub his hands with soap of the dispenser. With circular motions he cleans under his nails, between the fingers, on his hands and arms up to the elbows. He scrubs in for at least three minutes and dries his hands with a sterile towel. Additionally he uses an antiseptic alcohol-based hand rub and waits till his hands are dry. The nurse also applies the hand rub and opens up a set consisting of a long-sleeved sterile surgical gown and sterile gloves for the neonatologist. She makes sure to open it in such way that she does not touch the sterile parts of the set. Being clean, but not yet clean enough, he moves on to the second stage and puts on the sterile gown and gloves while 
making sure not to touch the sterile outer surface of gown and gloves. The nurse fixes the gown on his back. When she is done, he walks from the sink to the incubator, making sure not to touch any non-sterile items or persons by walking carefully with his lower arms and hands in upright position and avoiding tables, chairs and other staff.

Through a process of scrubbing, gowning and gloving, the neonatologist is transformed into a 'sterile instrument' (Hirschauer, 1991). To become a 'sterile instrument', requires more, however, than just 'washing your hands and dressing yourself. Transforming the doctor's body into a 'sterile instrument' is all about parts and places: between the fingers, inside the gloves, the front side of the gown, as well as the furniture and other people on the ward. It requires, I would argue, a topical focus: where to wash the hands and where to touch the gown and gloves, how to cross the ward. This focus is essential for the production of a sterile instrument. Moreover, during the transformation the focus of attention shifts from one place to another: from specific parts of the body (hands and arms) to specific parts of the gown and gloves (outside) and to specific parts of the ward (the area between the sink and the incubator). The focus of attention is captured by the locus of sterility.

\section{Next to the incubator: the level of mobility and the degree of sterility}

While the doctor is busy scrubbing in, the nurse opens the incubator and switches on the heater above. She positions the baby on her back and fixes one of her arms and both legs to make sure she will not move around.

During the insertion procedure, it is not only the baby who is restricted in her movements. To preserve the level of sterility, the mobility of the staff and material is restricted since the ward is a non-sterile space. As such, the degree of mobility and the level of sterility are tightly coupled. This restricted mobility implies that the moment the neonatologist starts the insertion procedure everything and everyone that is needed should be within reach. Anticipating the mobility restriction, the nurse starts to collect all the equipment that is needed. To do this, she moves the cart with instruments from the corner of the ward and positions it next to the incubator. An instrument trolley is positioned between the cart and the incubator. Subsequently folding screens are put around the cart, the trolley and incubator. After re-arranging the spatial order around the incubator (Fig. 2), the nurse takes a checklist, opens the drawers of the cart and gathers the materials.

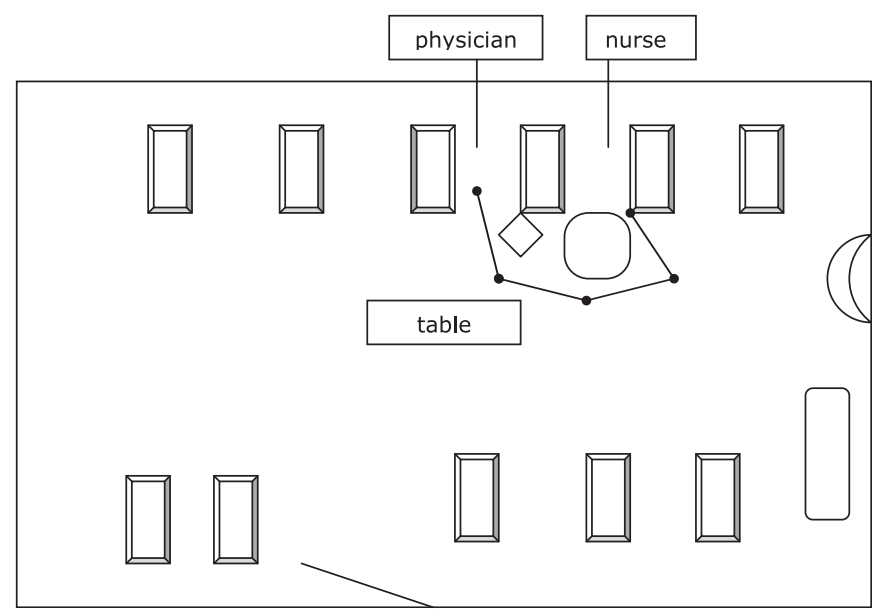

Fig. 2. Explanatory sketch of the spatial arrangement during the insertion procedure.
To insert a central catheter, one also needs resources of a different kind, such as the sealed set of equipment and the gloved hands of a neonatologist. Initially, these 'items' are distributed across the ward. They can be found next to the sink, in some corner in a cart and even in the sterile services unit. This implies that a standard procedure such as inserting a central line requires a convergence of these spatially distributed resources of sterility. In other words, the spatial re-arrangement of the area around the incubator facilitates the convergence of the spatially distributed resources into a single, integrated sterile tool.

\section{The instrument trolley: assembled in readiness}

In the meantime, the neonatologist has joined the nurse into the screened off space and positions himself at one side of the incubator and next to the trolley. The nurse has positioned herself between the cart and the trolley. With his sterile gloves the neonatologist opens the sterile set and displays its content on the sterile drape on the trolley. The nurse opens carefully without touching the content - the sealed packaging of the different items she has collected on top of the cart and 'drops' them on the sterile drape.

After the assembly of pieces of furniture and human bodies around the incubator, the process of convergence of the spatially distributed resources continues and shifts to another level and another place. From the area around the incubator, the locus of convergence zooms in on the space on the instrument trolley. By opening the sterile set, the trolley is transformed into a sterile field where the distributed instruments, sterile packages and drapes, skilful hands and attention, come together. Now this is the site where things are happening and on which the actors need to focus all their attention. Now this is their field of activity.

Hemmed in between the cart and the trolley, the nurse serves as intermediary with respect to the transfer of sterility from cart to trolley. Likewise, the neonatologist functions as the intermediary between trolley and incubator. This chain of intermediaries acts as a 'human passageway' and transforms the sequential steps of the procedure into a smooth trajectory on which sterility can travel from different corners of the ward to the incubator.

Aside from the sterile drapes, the set of equipment also includes tools for other kind of catheters. Therefore, the neonatologist has to select the items he needs for this specific procedure. He carefully arranges all the materials he has selected from the sterile set, as well as the items the nurse has tossed on the sterile field. However, instead of arranging them in a haphazard way on the sterile field, the neonatologist orders them as 'assembled groupings' (Lynch, Livingston, \& Garfinkel, 1983, p. 226). The different items are grouped together on the basis of their ties to other items. For instance, the specific parts that make up the catheter are grouped together, while the disinfectant tools for disinfecting the insertion site are positioned in another corner. The coherence of these groupings is not only based on the interrelationships between the items, but also on their position in the sequential order of the medical procedure. What needs to be used first, such as the disinfectant, is placed within easy reach. With the organization of the field of activity, the staff produces a practical constellation in which the items are arranged in such a way that they are in reach, and can easily be taken up and transported into the incubator. They are, in other words, 'assembled in readiness' (Lynch et al., 1983, p. 227).

The collection and spatial ordering of materials, staff and technology provides an orderly structure that facilitates the sequential steps to be taken in order to prepare the insertion of the catheter. The specific compositional order of materials and equipment directs the focus of the attention and the locus of the hands and, as 
such, acts as the infrastructure of attention. As Hirschauer (1991, p. 284 ) has shown in his description of the 'infrastructure of operations' of surgeons, the ordering of material is of utmost importance for carrying out complex action. This physical ordering does not only facilitate the hands, but also the head. Kirsh and Maglio (1994, pp. 513, 514), therefore, refer to this as 'epistemic actions'.

\section{Inside the incubator: the instrumentalization of the baby's body}

When the neonatologist indicates he is ready, the nurse opens the side compartment of the incubator to give him enough room to manoeuvre. Now the nurse puts her hands through the doors at the other side of the incubator and holds up the baby's hand with disinfected gauze, while the neonatologist covers the baby with several sterile drapes leaving the baby's arm uncovered. After the child is fully covered he swabs the arm with disinfectants. While doing this he is very careful not to touch the non-sterile hand of the nurse.

In this phase of the procedure, the field of activity has moved inside the incubator (Fig. 3). With this move, the available space to act is further reduced. Now the activity field is so small that it only allows room for the hands of the staff and baby's body. To perform a medical procedure in this small sterile field, involves an aseptic disciplining that requires a high level of spatial coordination and the capability to move around in limited space. Like before, the neonatologist is not allowed to touch anything that is not sterile. But this time these items - such as the hand of the nurse that holds the baby's hand or the inside of the incubator - are quite near. This is why the neonatologist gives directions to the nurse to avoid accidental contact. Any contact and he will loss his sterile status and as such become a 'useless instrument' for gaining access to the baby's body (Hirschauer, 1991). Therefore, he wraps the baby's

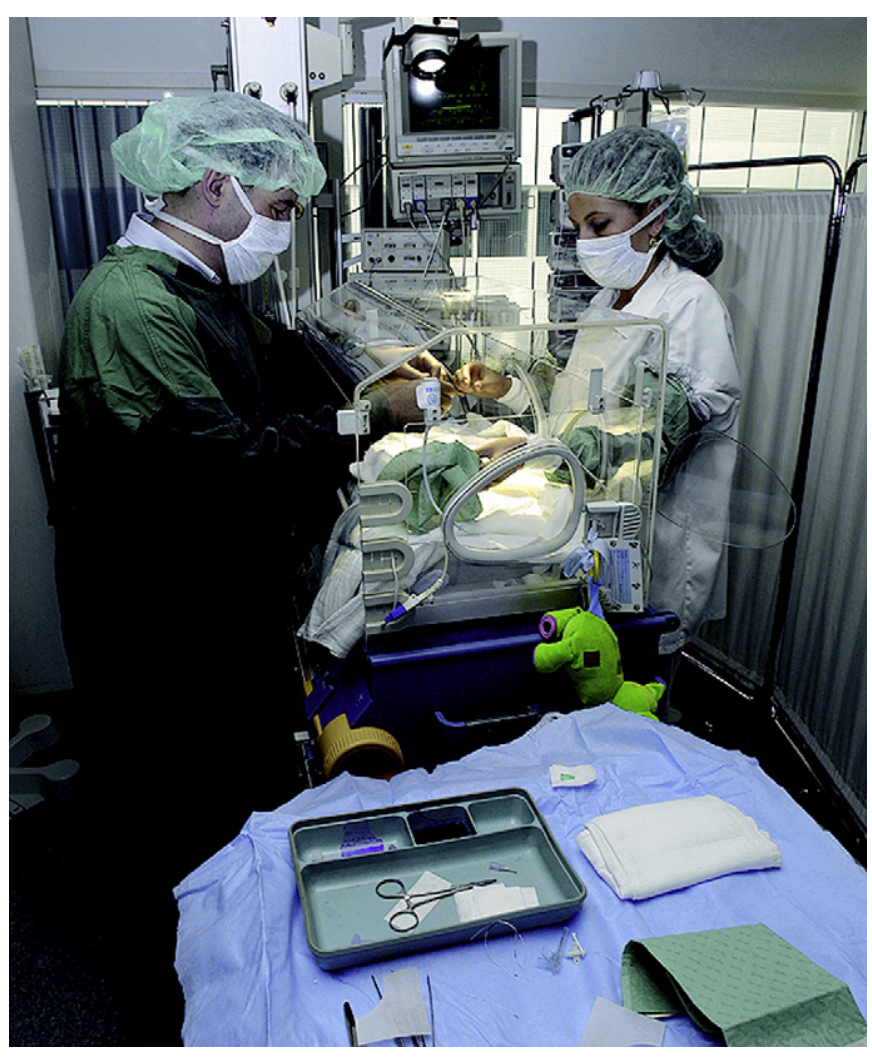

Fig. 3. During the insertion procedure (Courtesy Academic Hospital Maastricht). hand in a sterile drape and fixes it with a compress. Now the neonatologist can hold the hand of the baby up in the air himself and disinfect the arm for the second time. Moreover, by covering the baby's body with a sterile sheet he does not need to worry about touching the non-sterile parts of the baby and this gives him more freedom. Next, he takes the needle and catheter and some gauze from the sterile field on the instrument tray and brings it into the incubator and positions it on top of the sterile drapes which covers the baby. This 'instrumentalization of the patient-body' provides the neonatologist with an additional working bench (Hirschauer, 1991, p. 296). Now the activity field has moved into the incubator, on top of the baby.

\section{Into the vein: the reversal of scale}

With one hand the neonatologist gently squeezes the arm of the baby a little bit to improve the visibility of the veins. When he has found the right place he inserts the needle into the vein. To check if the needle is in the vein he carefully observes the appearance of blood. As the skin does not bulge he knows it is safe to insert the catheter into the needle. Gently he feeds the line through the needle into the vein until the numbers on the line indicate that it is in 8 centimetres.

The actual insertion of an intravenous catheter is a matter of location. The neonatologist has to be sure that the needle is in the vein, that the line is in the correct vein and that the line is not inserted too deep. Therefore, several safety checks are built into the procedure, such as the infusion of saline and the withdrawal of blood before the catheter line will be fed in. However, this is not sufficient since the vein is part of a large venous system and might get off track. Therefore, he also needs to check whether the line is still moving in the direction of the large vein that leads to the heart. Since the tip of the line has moved into the body, the neonatologist has to switch to another spatial coordination instrument. Now his hands take over what the eyes did before: verifying the location of the catheter. To prevent the line from going upwards, the baby's face is positioned to the other side. This makes it more difficult for the line to slip into the wrong vein. If needed, the neonatologist can pull back a little and try again. The further he gets in, the easier it is to feed the line in because closer to the heart the vein becomes wider. At this stage, the continuous reduction of space for manoeuvring has stopped; the reverse is in fact the case: from now on the amount of space goes up all the way until the procedure's completion.

\section{Nearby the heart: the abolishment of policy}

When the line is in position, the neonatologist removes the needle from the line. He puts the remaining part of the needle and contaminated gauzes back on the sterile field on the trolley. Now the line is in the correct position he winds up the rest of the line and arranges it as a small roll next to the insertion site. With careful precision both the line and the insertion opening are taped with a transparent sterile bandage that fits like a second skin to prevent the line from moving and bacillus from getting in.

From this moment on, the sterility policy can be abolished. The sterile 'second skin' functions as a buffer and secures the sterility of the insertion opening. The neonatologist removes the sterile drapes and folds up the sterile field on the tray table. The nurse connects the line to an intravenous system and adjusts the settings of the alarm and the monitor. She makes sure the child is comfortable and puts ready the infusion pumps. At last, she removes the folding screens, the cart and tray table. In this flow of activities, the activity 
field is enlarged again and relocated in the opposite direction: it moves from the vein back into the incubator, returning to the trolley and the area around the incubator. In the final stage of the procedure, the activity field involves other areas on the ward and elsewhere in the hospital.

\section{On the NICU and beyond}

The neonatologist takes off his sterile gown, mask and cap and walks over to the table in the centre of the NICU. In the patient record he writes down the date and time of insertion, the specific location of the line and its length. He sticks the label of the catheter type next to this information in the record. While he is taking care of this administrative duty, the nurse calls the Radiology department to ask for an x-ray to confirm the location of the line. In the meantime the line will be flushed with saline solution. After the x-ray confirmation they will switch to parental nutrition or IV-medication.

To accomplish a sterile line insertion involves spatial orderings of a different kind, like the convergence of the spatially distributed resources, the relocation of the field of activity, the assemblage of an infrastructure of attention, the composition of selected equipment on a sterile field, and the scaling down of one's degree of mobility and range of action. Sterility turns out to be a product of spatial orderings and, therefore, requires an adequate level of spatial awareness and spatial coordination. This, however, is just one side of the story, because the production of sterility also produces a specific spatial order. Sterility work maps out the ward in a specific order. Having analyzed the role of spatial ordering in the production of sterility, the next section will study how sterility work redefines the spatial order in the NICU.

\section{How sterile procedures produce spatial orders}

Michael Lynch (1991, p. 51) argues that place of work can be defined by what he calls 'locally organized topical contextures'. Space, according to Lynch, is organized in a contexture of activities. Action creates space, and in turn uses the structures this spatial order provides. Therefore, he argues, we should be concerned with the spatial grammars of particular practices (Lynch, 1991, p. 53). Following Lynch (1991), we can wonder how spatial grammars are topically tied to the complexities of safety activities. How, in other words, do complexes of technology and human actions related to safety activities, like the production and preservation of sterility, transform the spatial order of the ward?

Sterility is, I argue, all about space. Sterility can be regarded as 'carving out' a specific kind of space: one that is free from infectious micro-organisms. Hence, sterility is not only a product of spatial ordering, but also a property of space. The production of sterility involves the production of a spatial order. Sterility work generates particular spatial orders. In other words, sterility and spatial order are co-produced in the same process. Sterility can be regarded as a preventive practice with a specific mode of ordering in which architecture, materials, and social relations are folded together (cf. Law, 1994). To study the spatial order that results from these protective activities, I will first focus on the buffers and boundaries that these actions produce. Next, I will concentrate on the way sterility travels over the NICU ward and the co-existence of a multiple spatial orders.

\section{Buffers and boundaries}

All the work being done is aimed at keeping the germs outside the baby's body during and after the catheter is put in place. To accomplish this delicate task, the staff members have to set up a series of buffers. These protective activities involve boundary work of all kinds across contexts, type of groups and levels of different nature (Lamont \& Molnar, 2002). The way I use boundary work in this text should not be confused with Thomas Gieryn's notion of 'boundary work' that refers to the demarcation activities of scientists to draw a distinction between science and non-science (Gieryn, 1983). The same counts for 'boundary object' - a concept coined by Star and Griesemer (1989, p. 393) - '(...) an object plastic enough to adapt to local needs and the constraints of the several parties using them, yet robust enough to maintain a common identity across sites'. Although both concepts have proven their analytical strength in science studies and belong to the core concepts of the field, these specific definitions are not relevant in the context of this article. Instead, in this article, I restrict myself to spatial boundaries. In producing these barriers, the spatial order of the ward is reframed into special zones and specific areas. From the periphery (the sink) to the centre (incubator), we see an increasing degree of cleanliness that flows into sterility. However, these protective activities do not only map the ward into clean and dirty domains. While creating buffers against germs, other kinds of spatial arrangements are constituted as well. Let us take a closer look at the co-production of buffers and these spatial boundaries.

As we have seen in the former section, one way to establish a buffer against germs is the spatial re-arrangement of the material environment of the ward. By arranging the folding screens around the incubator, the nurse creates an inside and outside boundary. Through this 'boundary work', she constitutes a 'closed activity field' that is large enough to contain people, a cart, a trolley and an incubator with its technological equipment. The moment the neonatologist enters the area inside the folding screens, this part of the ward is considered as a restricted area that requires a proper outfit and knowledge of proper conduct. Indeed, where sterility reigns supreme, most of us do not. Moreover, upon entering this area, one is supposed not to leave it until the very end of the procedure. Now inside is the area of immobility, while at the other side of the screens everyone can walk around freely. Additionally, the screens shield off distraction and help the staff to hold on to a state of optimal concentration. As such, the screens create an area of attention and contribute to prolonging a particular mental state. Although the screens cannot be considered as a solid buffer against germs, they clearly indicate a boundary between inside and outside. Similarly, the airlock and separation box, the incubators, and the transparent second skin on the insertion site act as buffers and boundaries.

Besides the material markers there are also symbolic markers, like colours and rituals, which indicate a boundary between the sterile and non-sterile zone. These symbolic markers are conceptual distinctions that are part of (medical) practice and enable the practitioners involved to categorize objects, people and practices as being 'sterile' (Lamont \& Molnar, 2002). After all, the naked eye is not able to see what parts and areas are sterile or non-sterile. Therefore, artificial markers have to help us to designate its presence and boundaries. In this specific context, the colour 'green' acts as a symbolic resource that visualizes sterility. For example, the green sheets and drapes indicate a field of sterility and the instruments on top of them as being sterile, and as such oblige a 'do not touch' and 'keep at a distance, unless...' behaviour. Similarly, the moment the neonatologist is 'in green', no one is allowed to touch him anymore except his back to fix his gown. Katz (1981) argues that ritualistic behaviour contributes to the efficiency of activities when one lacks a clear-cut boundary between clean and dirty. Rituals like scrubbing and gowning, according to Katz, enable staff members to function in circumstances of ambiguity by providing a behavioural structure to distinguish sterile parts from non-sterile parts and help clarify categories and boundaries which 
are potentially confusing (cf. Hirschauer, 1991, 1994; Macqueen, 1995; Rawlings, 1989).

Other activities aimed at securing sterility reconfigure the spatial order in different ways. For instance, while the neonatologist is transforming himself into a sterile instrument, the area close to the sink has to be considered as his 'private' area. No one else is allowed to share the sink with him while he is busy scrubbing. At this point, all other activities that involve water or dirt are redirected to the other corners of the ward. The ensuing 'territorialisation' of one part of the ward now imposes an unbalanced spatial distribution of persons and activities across the ward.

Sterile procedures generate buffers and boundaries of all kinds. As a result, the ward is mapped out into different types of space: open spaces and restricted spaces, spaces where you can move freely and spaces where you have to stay put, accessible and inaccessible spaces, and 'private' and 'public' spaces. However, during the procedure the boundaries of these disparate domains shift, dissolve and sometimes reappear. Boundaries between specific 'open access areas' and 'restricted areas' move from one side of the ward (sink) to the other side of the ward (next to the incubator). But the 'private' domain of the neonatologist at the sink dissolves the moment he walks away. There is no fixed spatial order, no fixed centre of activity, and no fixed sterile place (cf. Law, 1994). Sterility travels from place to place, from object to object, from person to person, just like germs. But unlike germs, this journey requires a well-orchestrated 'chain of replacements' from one field of activity to another (Latour, 1995, p. 175). With every replacement, the spatial order on the ward is mapped out in different domains along other axes. Sterility, because of its artificial nature, implies a dynamic of fluidity, of constantly shifting territorialisation within the NICU, and while it travels it reconfigures the spatial order of the NICU. As such, this spatial order is a transient order with its own dynamic. Yet, with every replacement, the boundaries of the sterile zone need to be staked out, fixed and conditioned to prevent contamination (Livingstone, 2003). To maximize their control of the 'safety spots', the NICU staff use a strict access policy. This policy affects the spatial map of the whole ward: it becomes a working space where some places are not available for some time, some persons and objects cannot be touched and one is not allowed to enter some spaces unless one takes the required measures.

\section{The co-existence of spatial orders}

The NICU is a place where different practices interconnect: caring practices, therapeutic practices, family practices, dying practices, and research practices. The frames of architecture, the complexes of technology and human actions related to these aims map out the spatial order on the ward as well. The intersection of these different lines of activity results in a co-existence of disparate spatial orders. Instead of one, there is a multitude of spatial arrangements: a sterile space, a treatment zone, a place of caring and comfort, a place where parents meet their child, and a place where their child dies or recovers. As such, the NICU resembles with what Foucault refers to as a 'heterotopia', which is "a heterogeneous topos, a relatively segregated place in which several spatial settings co-exist" (Ophir \& Shapin, 1991, p. 13).

A lot of the locations involved in the spatial arrangement of producing sterility belong to other lines of activity as well. For instance, the area around the sink is also part of cleaning and caring activities. It is the place where you leave your garbage or use tap water to wash a baby. The area next to the incubator is also the location where parents visit their child, where research is done, where babies are fed, and monitored. Likewise, the isolation box is not only the room where new admissions from outside the hospital are assigned to in order to prevent contamination; the box is also the place where children can die, since it is the only space on the ward that provides some privacy. When these lines of activity meet, a normative structure becomes visible. One spatial meaning is prioritized over another: when the doctor scrubs in, the nurse has to wait before she can bathe a baby, throw away her garbage or take out the bottle to feed a child. The spatial arrangement of caring and cleaning has to give way to that of sterility. Likewise, the parents have to wait outside before they can take a seat next to the incubator of their child. Similarly, a resident has to wait till the nurse and the neonatologist have finished, before he or she can undertake the daily examination of the child. The space to care competes with the space to cure. The space to die competes with the space to prevent contamination. There is a hierarchy between spatial orders, and sterility holds a strong position. But this ranking is not fixed. If there is a crisis, resuscitation is the first priority and every buffer and boundary regarding sterility will be passed over. The hierarchical order is the outcome of a negotiating process and as such never permanent, nor automatic.

The overall picture shows us how NICU staff create spheres of inaccessibility to get access to the baby's body. Inaccessible for other staff members, for parents, and for objects, because they all are potential containers of germs. Moving from the periphery to the final locus of action (the insertion site) the space of accessibility becomes smaller. With every step the actors take, the accessible area diminishes in size and the restriction policy becomes more stringent. It compels people and things to stay behind the fence. In the end, it is only the needle that is allowed to get in.

\section{Patient safety and spatial order: some concluding remarks}

Many studies of patient safety are geared towards prevention of adverse events by detecting and eliminating causes of error. In this paper, I have argued that patient safety research needs to widen its analytical scope and include adequate and reliable practices as well. Although various qualitative aspects of the contemporary medical practice have been studied thoroughly, there is still little insight into the complicated interplay of specific ways of reasoning and acting associated with a successful preservation of patient safety in complex care situations. Therefore, as I have argued in the paper, we should not only study the explicit, formal safety measures and protocols, but also analyze the unarticulated set of actions that is involved in day-to-day operations. By analyzing 'common' interventions, like an insertion of a central venous catheter, we can explicate the self-evident actions involved and their potential for safe practice.

As a method, a geographical analysis provides flexibility in scale of focus and range of application (Andrews \& Moon, 2005b). The focus can range from national health care systems to small sterile fields. As safety activities are situated in a spatial-temporal order, the range of potential topics is huge. Results of these kinds of studies can open up new opportunities for reinforcing what is already strong, by increasing practitioners' awareness of their spatial resources.

A focus on the spheres of action enables us to define the spatial dynamics that are involved in an insertion procedure and its sterility work in particular. First, it has provided a map of the spatial distribution and redistribution activities and attention on the critical care unit. Second, and more important, it has demonstrated how, besides the content of the formal protocol, other modes of knowledge, like spatial competence, and other kinds of concern, like competing lines of activities or navigating through a nonsterile area, play a crucial role in patient safety. In other words, a topical analysis of sterility demonstrates how space matters in the production and preservation of patient safety, and sterility in particular. 
Sterility is about carving out a specific space; about creating boundaries and buffers; about staging a trajectory over which sterility can travel from the different corners of the ward all the way into the incubator and into the infant's vein. Spatial ordering turns out to be a constitutive part of the accomplishment of sterility. A topical analysis of a line insertion shows how spatial arrangements facilitate an efficient convergence of distributed resources of sterility. In addition, these arrangements constitute infrastructures of attention, which help staff members to keep focused' and to perform sterility work in a limited amount of time. Time reduction is an important aspect of sterility work since it reduces the time for bacteria to enter the sterile field. Furthermore, spatial awareness and coordination proves to be relevant to operate safely within a diminishing space and brings about preparatory measures to avoid unnecessary actions through the NICU space.

Moreover, a topical analysis of patient safety provides another conceptualisation of both patient safety and space. Space in this perspective is not the passive environment in which people move around and activities occur, but an active 'doing' that takes part in the constitution of patient safety. By analyzing processes of spatial fine-tuning in everyday practice, it becomes possible to identify spatial competences and circumstances that enable staff members to provide safe care. This kind of analysis will increase the 'safety sensibility' of practitioners in another way as it offers an alternative image of patient safety, one that takes into account, among other things, its spatial dimension. As being major constituent of intervention practices, location and motion play an important role in the preservation of patient safety. Therefore, they should get the attention they deserve.

\section{References}

Andrews, G. J. (2003). Locating a geography of nursing: space, place and the progress of geographical thought. Nursing Philosophy, 4, 231-248.

Andrews, G. J., \& Moon, G. (2005a). Space, place, and the evidence base: part I - an introduction in health geography. Worldviews on Evidence-Based Nursing, 2(2), 55-62.

Andrews, G. J., \& Moon, G. (2005b). Space, place, and the evidence base: part II rereading nursing environment through geographical research. Worldviews on Evidence-Based Nursing, 2(3), 142-156.

Carolan, M., Andrews, G. J., \& Hodnett, E. (2006). Writing place: a comparison of nursing research and health geography. Nursing Inquiry, 13(3), 203-219.

Department of Health. (2000). An organisation with a memory. Report of an expert group on learning from adverse events in the NSH. London: TSO.

Gieryn, T. F. (1983). Boundary-work and the demarcation of science from nonscience: strains and interests in professional ideologies of scientists. American Sociological Review, 48(6), 781-795.
Gieryn, T. F. (2002). What buildings do. Theory and Society, 31, 35-74.

Gilmour, J. A. (2006). Hybrid space: constituting the hospital as a home space for patients. Nursing Inquiry, 13(1), 16-22.

Hetherington, K., \& Munro, R. (Eds.). (1997). Ideas of difference (pp. 183-199). Oxford: Blackwell Publishers.

Hirschauer, S. (1991). The manufacture of bodies in surgery. Social Studies of Science, 21, 279-319.

Hirschauer, S. (1994). Towards a methodology of investigations into the strangeness of one's own culture: a response to collins. Social Studies of Science, 24, 335-346.

Katz, P. (1981). Rituals in the operating room. Ethnology, 20(4), 335-350.

Kirsh, D., \& Maglio, P. (1994). On distinguishing epistemic from pragmatic action. Cognitive Science, 18, 513-549.

Kohn, L. T., Corrigan, J. M., \& Donaldson, M. S. (2000). To err is human. Building a safer health system. Washington, DC: National Academic Press.

Lamont, M., \& Molnar, V. (2002). The studies of boundaries in the social sciences. Annual Review of Sociology, 28, 167-195.

Latour, B. (Spring 1995). The "Pédofil" of Boa Vista: a photo-philosophical montage. Common Knowledge, 4, 144-182.

Law, J. (1994). Organizing modernity. Oxford: Blackwell.

Livingstone, D. L. (2003). Putting science in place: Geographies of scientific knowledge. Chicago: The University of Chicago Press.

Lynch, M. (1991). Laboratory space and the technological complex: an investigation of topical contextures. Science in Context, 4(1), 51-78.

Lynch, M., Livingston, E., \& Garfinkel, H. (1983). Temporal order in laboratory work. In K. Knorr-Cetina, \& M. Mulkay (Eds.), Science observed: Perspectives on the social studies of science (pp. 205-238). London: Sage Publication.

Macqueen, S. (1995). Anthropology and the germ theory. Journal of Hospital Infection, 30, 116-126.

Malone, R. E. (2003). Distal nursing. Social Science \& Medicine, 56, 2317-2326.

Mesman, J. (2008). Uncertainty in medical innovation. Experienced pioneers in neonatal care. New York: Palgrave MacMillan.

Ophir, A., \& Shapin, S. (1991). The place of knowledge. A methodological survey. Science in Context, 4(1), 3-21.

Rawlings, B. (1989). Coming clean: the symbolic use of clinical hygiene in the hospital sterilising unit. Sociology of Health E Illness, 11(3), 279-293.

Rizzo, M. (2005). Striving to eliminate catheter-related bloodstream infections: a literature review of evidence-based strategies. Seminars in Anesthesia, 24, $214-225$.

Rubinson, L., \& Diette, G. (2004). Best practices for insertion of central venous catheters in intensive-care units to prevent catheter-related bloodstream infections. The Journal of Laboratory and Clinical Medicine, 143, 5-13.

Sharma, S., Smith, A. F., Rooksby, J., \& Gerry, B. (2006). Involving users in the design of a system for sharing lessons from adverse incidents in anaesthesia. Anaes thesia, 61, 350-354.

Sheretz, R. J., Wesley Ely, E., Westbrook, D. M., Gledhill, K. S., Streed, S. A., Kiger, B. et al. (2000). Education of physicians-in-training can decrease the risk for vascular catheter infection. Annals of Internal Medicine, 132, 641-648.

Smith, A. F., Goodwin, D., Mort, M., \& Pope, C. (2006). Adverse events in anaesthetic practice: qualitative study of definition, discussion and reporting. British Journal of Anaesthesia, 96, 715-721.

Smith, C., \& Agar, J. (Eds.). (1998). Making space for science. Territorial themes in the shaping of knowledge. Houndsmill: Macmillan.

Star, S. L., \& Griesemer, J. R. (1989). Institutional ecology, translations' and boundary objects: amateurs and professionals in Berkeley's Museum of Vertebrate Zoology, 1907-39. Social Studies of Science, 19, 387-420.

Wilde de, R. Innovating innovation: a contribution to the philosophy of the future Paper read at Policy Agendas for Sustainable Technological Innovation, 1-3 December 2000, London. 